\title{
Risk Factors for Gambling Problems: An Analysis by Gender
}

\author{
Nerilee Hing $^{1} \cdot$ Alex Russell $^{1} \cdot$ Barry $_{\text {Tolchard }}{ }^{2,3}$. \\ Lia Nower ${ }^{4}$
}

Published online: 7 May 2015

(C) Springer Science+Business Media New York 2015

\begin{abstract}
Differences in problem gambling rates between males and females suggest that associated risk factors vary by gender. Previous combined analyses of male and female gambling may have obscured these distinctions. This study aimed to develop separate risk factor models for gambling problems for males and for females, and identify gender-based similarities and differences. It analysed data from the largest prevalence study in Victoria Australia $(N=15,000)$. Analyses determined factors differentiating non-problem from atrisk gamblers separately for women and men, then compared genders using interaction terms. Separate multivariate analyses determined significant results when controlling for all others. Variables included demographics, gambling behaviour, gambling motivations, money management, and mental and physical health. Significant predictors of at-risk status amongst female gamblers included: 18-24 years old, not speaking English at home, living in a group household, unemployed or not in the workforce, gambling on private betting, electronic gaming machines (EGMs), scratch tickets or bingo, and gambling for reasons other than social reasons, to win money or for general entertainment. For males, risk factors included: 18-24 years old, not speaking English at home, low education, living in a group household, unemployed or not in the workforce, gambling on EGMs, table games, races, sports or lotteries, and gambling for reasons other than social reasons, to win money or for general entertainment. High risk groups requiring appropriate interventions comprise young adults, especially males; middle-aged female EGM gamblers; non-English speaking populations; frequent EGM, table games, race and sports gamblers; and gamblers motivated by escape.
\end{abstract}

Nerilee Hing

nerilee.hing@scu.edu.au

1 Centre for Gambling Education and Research, Southern Cross University, PO Box 157, Lismore, NSW, Australia

2 School of Health, University of New England, Armidale, NSW, Australia

3 School of Health and Human Sciences, University of Essex, Colchester, UK

4 Center for Gambling Studies, Rutgers University, New York, NY, USA 
Keywords Problem gambling · Pathological gambling $\cdot$ Risk factors · Gender · Male · Female $\cdot$ Prevalence study

\section{Introduction}

Prevalence studies in numerous jurisdictions consistently report at least double the rate of problem gambling amongst males compared to females (Williams et al. 2012a). This suggests that risk factors for problem gambling may differ between men and women, although related research is inconclusive (Delfabbro 2012; Johansson et al. 2009). While risk factors do not presume causation, their identification allows recognition and targeting of high-risk groups for prevention, early intervention and treatment strategies (Perese et al. 2005; Thomas and Jackson 2008). A gendered understanding of these risk factors can inform design of public health campaigns and promotion of treatment services appropriately targeted to each gender.

This study aimed to develop separate risk factor models for gambling problems for males and for females, and identify any gender-based similarities and differences. By using multivariate techniques to analyse an existing dataset, it overcame limitations of previous studies identifying correlates with problem gambling, but which have been criticised for ignoring statistical overlap amongst risk factors (Delfabbro 2009; Productivity Commission 2010). The following brief literature review focuses on variables of interest in the current study - demographics, gambling behaviour, gambling motivations, and health.

\section{Demographics}

Reviews have consistently concluded that young males (18-30 years) are overrepresented amongst problem gamblers, while unemployment, divorced and single marital status, reliance on social welfare, low income, low education, and ethnic minority status have also been correlated (Delfabbro 2012; Johansson et al. 2009; Williams et al. 2012a, b). However, these generic risk factors have typically been derived from combined analyses which have not considered distinctive risk factors by gender.

Prevalence and gender-specific studies have illuminated some demographic differences in risk factors. Compared to males, females are typically older at gambling commencement and problem development and more quickly progress to problem gambling, reflecting a telescoping phenomenon (Blanco et al. 2006; Castrén et al. 2013a; Crisp et al. 2004; Tavares et al. 2001; Wenzel and Dahl 2009). Studies of treatment-seeking gamblers have identified further demographic gender differences. Amongst males $(n=826)$ and females $(n=694)$ attending problem gambling counselling in Victoria Australia, female clients were more likely to be Australian born, married, living with family and dependent children, and have substantially lower gambling debts (Crisp et al. 2004). A review of gender differences in treatment-seeking gamblers (Wenzel and Dahl 2009) found inconclusive evidence for marital status, but moderate evidence that female clients have lower incomes compared to males.

The emergence of Internet gambling may be changing the demographic profile of female problem gamblers. McCormack et al. (2014) suggest that gambling online may be a potential risk factor in females due to enhanced feelings of safety over land-based venues. Females in their study had earlier age of online gambling uptake than males. Women's 
uptake of Internet gambling may explain why recent research from many jurisdictions indicates rapid rises in female problem gambling, especially amongst younger women (Dowling 2013). A recent Tasmanian prevalence study found no differences in problem gambling rates between males and females (Christensen et al. 2014). Conversely, a study in the US where Internet gambling is less available found that younger female gamblers had lower problem gambling rates than younger male gamblers (Wong et al. 2013).

\section{Gambling Behaviour}

Gambling on multiple forms is consistently associated with problem gambling, with males typically gambling on more forms than women (Gainsbury et al. 2014; Welte et al. 2004; Wenzel and Dahl 2009). Males are also more likely than females to participate regularly in most gambling forms (Svensson et al. 2011), and to gamble more frequently and with higher expenditure (Hing and Breen 2001a, b). Continuous gambling forms are associated with increased risk (Delfabbro 2012; Williams et al. 2012b), with EGMs the main source of difficulties amongst most problem gamblers, and associated with 75-80 \% of gambling-related problems in Australasia (Delfabbro 2012). Women show higher risks for problem gambling on nonstrategic forms such as EGMs and bingo (Binde 2011; Grant et al. 2012), and experience gambling problems almost exclusively with EGMs (Delfabbro 2012; Holdsworth et al. 2012; Productivity Commission 2010). Problematic Internet gambling forms are sports and race wagering, with related problems mainly experienced by men (Hing et al. 2014c). Skill based online gambling is associated with higher risk in males, and non-skill based online gambling with higher risk in females (McCormack et al. 2013; Wood and Williams 2011).

\section{Gambling Motivations}

Gambling to serve a psychological need increases likelihood of problem gambling (Williams et al. 2012b), especially if to escape from negative mood states (Blaszczynski and Nower 2002; Nower and Blaszczynski 2010). Women's greater use of EGMs as a maladaptive coping mechanism to escape stresses, loneliness and boredom is consistently associated with increased problem gambling risk (Lloyd et al. 2010; Sacco et al. 2011; Walker et al. 2005). Gambling to earn income has also been implicated as heightening risk of gambling problems (Lee et al. 2007; Nower and Blaszczynski 2010). Positive expectancies from gambling, such as excitement and money, predict problems in both men and women (Spurrier and Blaszczynski 2014). Lister (2014) found that chasing in EGM play was a significant predictor of problem gambling in males over females; however desire to win in females was a higher predictor of chasing than in males. Overall, there is strong evidence of gender differences in gambling motivations, with escape from negative emotions and problems a central motivator for female problem gamblers; being preoccupied with the game, cognitions about winning, and egotism are associated with male problem gambling (Wenzel and Dahl 2009).

\section{Health}

Problem gambling is highly co-morbid with mental and physical health problems (Petry et al. 2005; Welte et al. 2004), although causal directions are unclear. In terms of substance abuse, male treatment-seeking gamblers are more likely to report alcohol and other 
substance abuse, compared to female counterparts (Dannon et al. 2006; Martins et al. 2004; Wenzel and Dahl 2009). In the general population, nicotine use has been associated with female at-risk gamblers, and alcohol use disorder with male at-risk gamblers (Pilver et al. 2013). In relation to mental health, female treatment-seeking gamblers are more likely to report anxiety or mood disorders, with a review finding strong evidence for this association (Wenzel and Dahl 2009). In the general population, a large representative US study (Petry et al. 2005) identified significant associations between pathological gambling and alcohol use and drug use disorders, and mood, anxiety and personality disorders amongst both men and women. However, relationships between pathological gambling and alcohol dependence, any drug use disorder, drug abuse, nicotine dependence, major depression, and generalised anxiety disorders were significantly greater for women. Problem gambling is also associated with poorer general health (Erickson et al. 2005; Petry 2006; Pietrzak et al. 2005) and a range of specific conditions, including tachycardia, angina, cirrhosis and other liver disease, along with higher medical utilisation (Morasco et al. 2006). However, gender comparisons are scant. A representative Canadian study (Afifi et al. 2010) found numerous health conditions were more prevalent amongst problem gambling females, compared to non-problem gambling females. These included chronic bronchitis, fibromyalgia and migraines, along with lower general health.

In summary, the literature suggests that male and female problem gamblers may differ in terms of demographics, problematic gambling form, gambling behaviours and motivations, substance misuse, and a range of health conditions. This study investigated which of these factors are salient in separate risk factor models for men and for women.

\section{Methods}

\section{Recruitment and Sampling}

New analysis was conducted of data from A Study of Gambling in Victoria Australia (Hare 2009), the largest gambling study in that jurisdiction. Conducted between August-October 2008, 15,000 adults (18 years+) were surveyed. Data were weighted to ensure close alignment with the Victorian adult population.

\section{Measures}

Problem Gambling Severity Index (PGSI; Ferris and Wynne 2001) The 9-item PGSI was administered to all gamblers. Unlike the validated version, responses were asked and scored as never $=0$, rarely $=1$, sometimes $=1$, most of the time $=2$, and always $=3$. Cut-off scores were $0=$ non-problem gambler, $1-2=$ low risk gambler, $3-7=$ moderate risk gambler, and 8-27 = problem gambler. Cronbach's alpha $=0.87$.

Gambling behaviours during the past 12 months Participation in 11 gambling forms (listed in Table 2) was assessed with yes/no responses, and frequency as number of times per week/month/year (converted to yearly).

EGM gambling EGM gamblers were asked how many venues (including Internet sites) they had gambled on EGMs at, frequency of betting more than one credit per line and denomination mostly played.

Race wagering Race wagerers were asked their three main bet types. 
Money management for gambling on highest spend activity in past 12 months Variables measured were how much cash and whether respondents typically brought debit and credit cards to the venue, and the number of times they used these cards per session.

Main three reasons for gambling on highest spend activity Response options were social reasons, win money, general entertainment, takes your mind off things, relieves stress, boredom, and other (free response).

Smoking Whether the respondent had smoked in the past 12 months and whether they currently smoked were measured.

Alcohol consumption The 4-item CAGE alcohol screen (Ewing 1984) measured the risk of clinically significant alcohol abuse.

Mental health The Kessler 10 was used as a global measure of psychological distress. Responses were measured from $1=$ none of the time to $5=$ all of the time. Cut-off scores were $10-19=$ likely to be well, $20-24=$ likely to have a mild mental disorder, 25-29 = likely to have a moderate mental disorder, and 30-50 = likely to have a severe mental disorder.

Physical health Respondents were asked to rate their overall health (from $1=$ excellent to $5=$ poor), whether they had experienced major problems, hardship or trauma in their life, and whether they currently had eight specific health conditions.

Socio-demographics Questions established respondents' age, gender, language other than English spoken at home, education, household composition and employment status.

\section{Analysis}

Due to minimal risk of problematic gambling, respondents participating in private betting, keno, lottery-type games, instant scratch tickets, bingo, phone/SMS competitions, and raffles/sweeps/other competitions less than once a month (and not participating in any other forms) were excluded. Of the 11,235 gamblers, 2304 met these criteria.

As only $0.7 \%$ of the sample met criteria for problem gambler, they were combined with moderate risk gamblers in an "at-risk" (AR) group (PGSI 3+) which was compared to a "non-problem gambler" (NP) group (PGSI 0-2). After weighting, the number of included respondents was 8917, with 463 (5.2\%) at-risk (284 males, 179 females).

Analyses determined which factors differentiated non-problem from at-risk gamblers separately for women and men (i.e. simple effects). Results for females and males were then compared using interaction terms. Due to possible overlap, separate multivariate analyses determined which results were significant when controlling for all others. All analyses were conducted using a $p$ value (alpha) of 0.05 or lower.

Table 1 PGSI categories by gender

\begin{tabular}{lllll}
\hline & \multicolumn{2}{l}{ Females } & & \multicolumn{2}{l}{ Males } \\
\cline { 2 - 3 } \cline { 5 - 5 } & $\mathrm{N}$ & $\%$ & $\mathrm{~N}$ & $\%$ \\
\hline Non-problem gambler & 3903 & $88.6^{\mathrm{a}}$ & 3.738 & 82.9 \\
Low risk gambler & 324 & 7.4 & 489 & $10.8^{\mathrm{a}}$ \\
Moderate risk gambler & 142 & 3.2 & 214 & $7.7^{\mathrm{a}}$ \\
Problem gambler & 37 & 0.8 & 70 & $1.6^{\mathrm{a}}$ \\
& $\chi^{2}(3, N=8917)=60.56, p<0.001, \Phi=0.08$ & \\
\hline
\end{tabular}

${ }^{a}$ Indicates the significantly higher proportion 


\section{Problem Gambling}

Significantly higher proportions of males scored as low risk, moderate risk and problem gamblers compared to females (Table 1). A significantly higher proportion of females were non-problem gamblers.

\section{Demographic Characteristics}

\section{Age}

For both genders, significantly higher proportions of at-risk gamblers were in younger age brackets compared to non-problem gamblers. Amongst males, those aged 18-34 years were more likely to be at-risk $\left(\chi^{2}(5, N=4510)=54.77, p<0.001, \Phi=0.11\right)$, as were females aged $18-24$ years $\left(\chi^{2}(5, N=4407)=19.12, p=0.002, \Phi=0.07\right)$. Conversely, both males and females aged 65 years + were significantly more likely to be non-problem gamblers compared to younger counterparts. A significant interaction indicated the pattern of results differed significantly across genders $\left(\chi^{2}(5, N=8919)=13.31, p=0.021\right)$. Younger males were more likely to be at-risk compared to younger females, while older females were more likely to be non-problem gamblers compared to older males.

\section{Language Spoken at Home}

For both genders, at-risk gamblers were significantly more likely to speak a language other than English at home compared to non-problem gamblers $\left(\chi^{2}(1, N=4407)=5.65\right.$, $p=0.017, \Phi=0.04$ for females and $\chi^{2}(1, N=4512)=22.19, p<0.001, \Phi=0.07$ for males). This difference did not differ by gender, $\chi^{2}(1, N=8919)=0.51$, ns.

\section{Education}

For both genders, at-risk gamblers were significantly more likely to cease education at Year 10 (females $48.9 \%$, males $36.4 \%$ ) compared to non-problem gamblers (females $35.2 \%$, males $28.2 \%$ ), while non-problem gamblers were significantly more likely to have attended university (females $25.3 \%$, males $27.2 \%$ ) compared to at-risk gamblers (females $15.5 \%$, males $17.7 \%), \chi^{2}(3, N=4356)=16.84, p=0.001, \Phi=0.06$ and $\chi^{2}$ $(3, N=4468)=16.80, p=0.001, \Phi=0.06$ respectively. There was no significant interaction between genders, $\chi^{2}(3, N=8813)=1.01, n s$.

\section{Household Composition}

Significant differences in household composition were observed for both genders (female $\chi^{2}(6$, $N=4392)=44.22, p<0.001, \Phi=0.10$ and male $\chi^{2}(6, N=4492)=48.41, p<0.001$, $\Phi=0.10$ ). For both genders, at-risk gamblers were significantly more likely to live in group households compared to non-problem gamblers (female AR $9.6 \%$, female NP $2.4 \%$, male AR $10.6 \%$, male NP $4.1 \%$ ). For females, a significantly higher proportion of at-risk gamblers lived in one-parent family households (14.1\% AR, 8.7 \% NP), whereas a significantly higher proportion of non-problem gamblers lived as couples with children (48.8\% NP, $40.7 \% \mathrm{AR}$ ). For males, a significantly higher proportion of non-problem gamblers lived as a couple without 


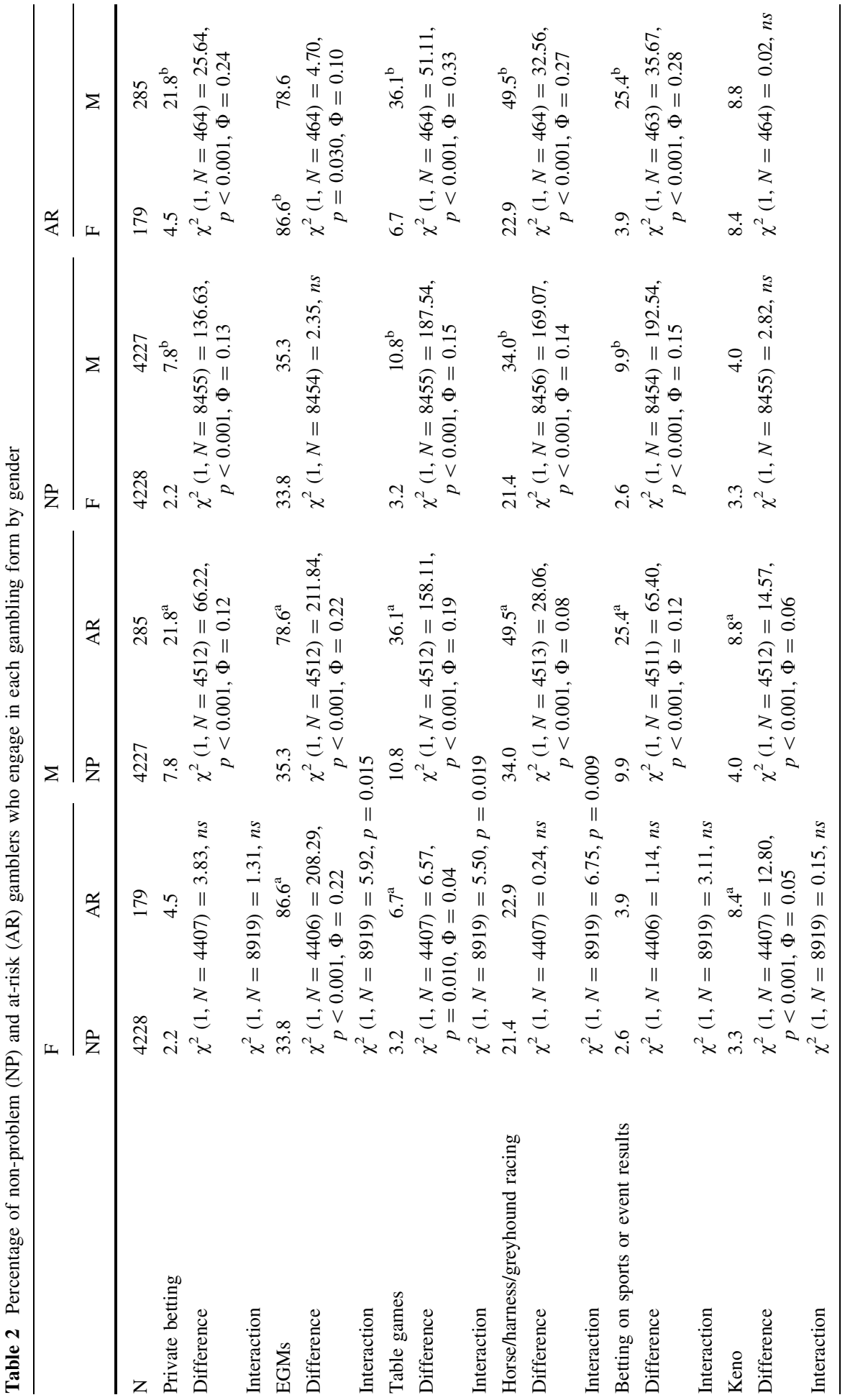




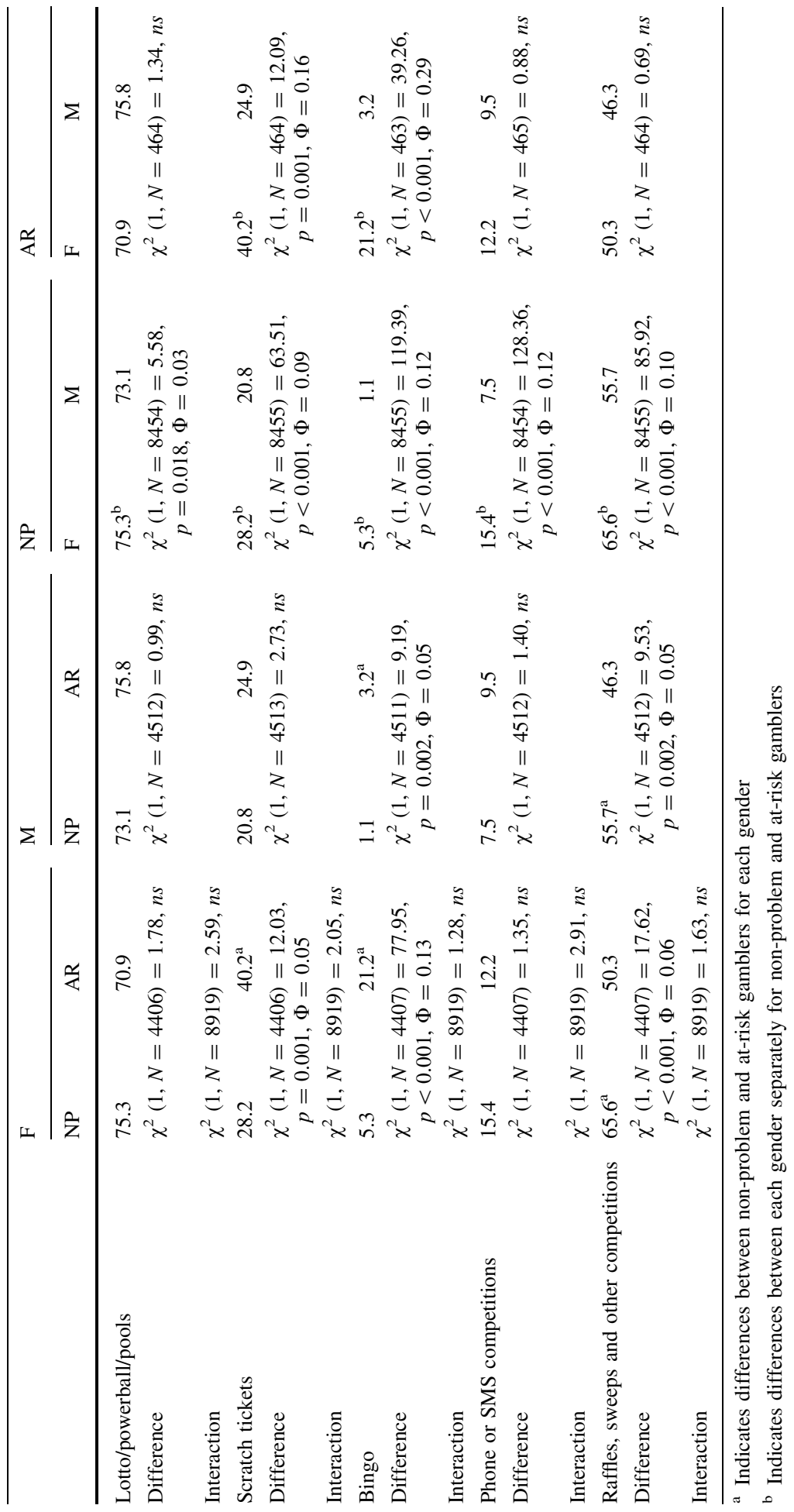


children (28.2 \% NP, $16.9 \%$ AR). No significant differences were observed between risk groups for either gender for other living arrangements. The overall omnibus interaction test between genders was not significant, $\chi^{2}(6, N=8893)=5.90, n s$.

\section{Employment}

Significant differences between risk groups were observed for both genders for employment $\left(\right.$ female $\chi^{2}(3, N=4404)=17.54, p=0.001, \Phi=0.06$, male $\chi^{2}(3, N=4506)=20.22$, $p<0.001, \Phi=0.07)$. Males in full-time employment were significantly less likely to be atrisk gamblers (NP $64.4 \%$, AR $55.4 \%$ ), while the opposite was true for males employed parttime (AR $19.3 \%$, NP $11.0 \%$ ). A significantly higher proportion of unemployed females were at-risk compared to non-problem gamblers (AR 7.8 \%, NP $2.8 \%$ ). No significant differences were observed between male risk groups or female risk groups for other employment categories. The relationship between employment status and at-risk gambling differed by gender, $\chi^{2}(3, N=8919)=12.67, p=0.005$. Female non-problem and at-risk gamblers were significantly more likely to not be in the workforce compared to male counterparts, while male non-problem and at-risk gamblers were significantly more likely to be employed full-time.

\section{Gambling Behaviour}

\section{Participation}

Risk groups of both genders were compared for participation in different gambling forms. Neither gender showed significant differences between risk groups for lottery-type games or phone/SMS competitions (Table 2).

For both genders, a significantly higher proportion of at-risk gamblers (compared to non-problem gamblers) participated in EGMs, table games, keno and bingo. Private betting, race and sports betting were related to at-risk gambling for men. Instant scratch tickets were related to at-risk gambling for women.

Males of both risk levels were significantly more likely to participate in private betting, table games, race and sports betting. Females of both risk levels were significantly more likely to buy scratch tickets and play bingo.

Interaction tests indicated that EGM participation was significantly more problematic for females than for males, while the opposite was found for table games and race betting. The same may be true for sports betting and bingo, but there were insufficient at-risk female sports betters and male bingo gamblers for results to reach statistical significance.

\section{Frequency}

Both genders were compared for gambling at least weekly/less than weekly on each form, with non-participants in each form excluded from analysis. No significant differences were observed between risk groups for either gender for frequency of private betting, lotterytype games or bingo (Table 3 ).

For both genders, those engaging at least weekly in EGMs, table games, race betting and instant scratch tickets were significantly more likely to be at-risk gamblers. The same was true for males on keno and sports betting, and for females on bingo, although based on small numbers. 


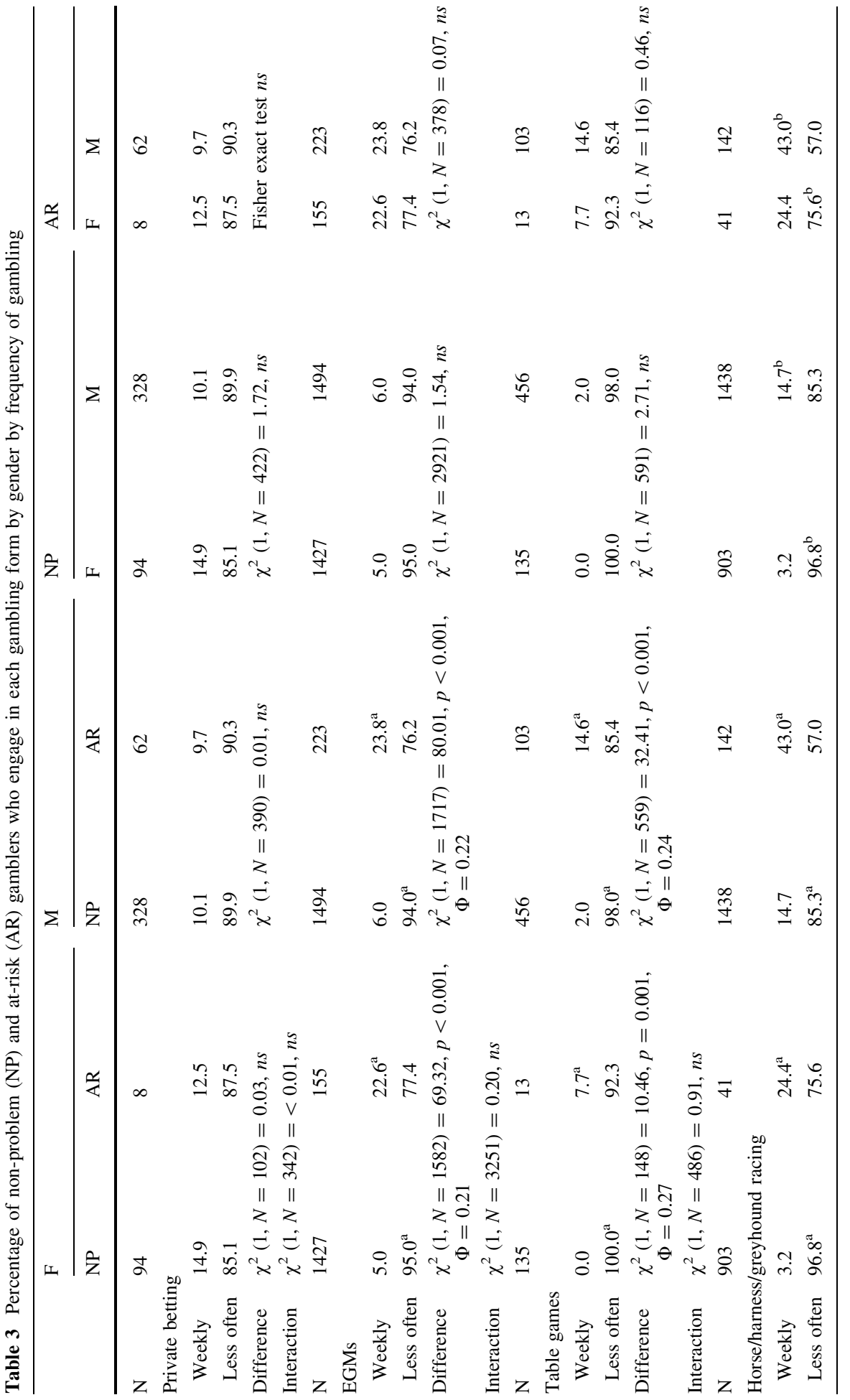




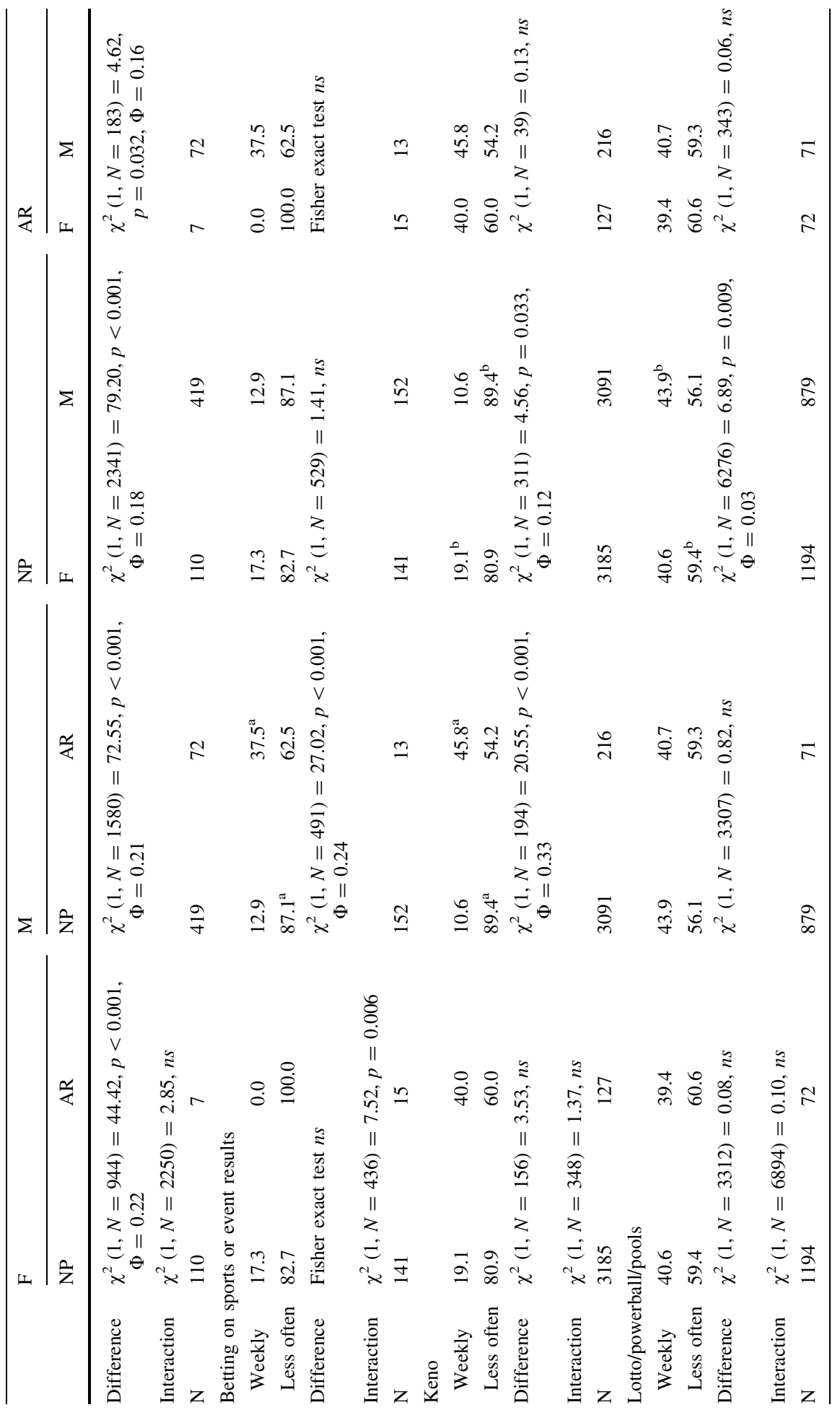




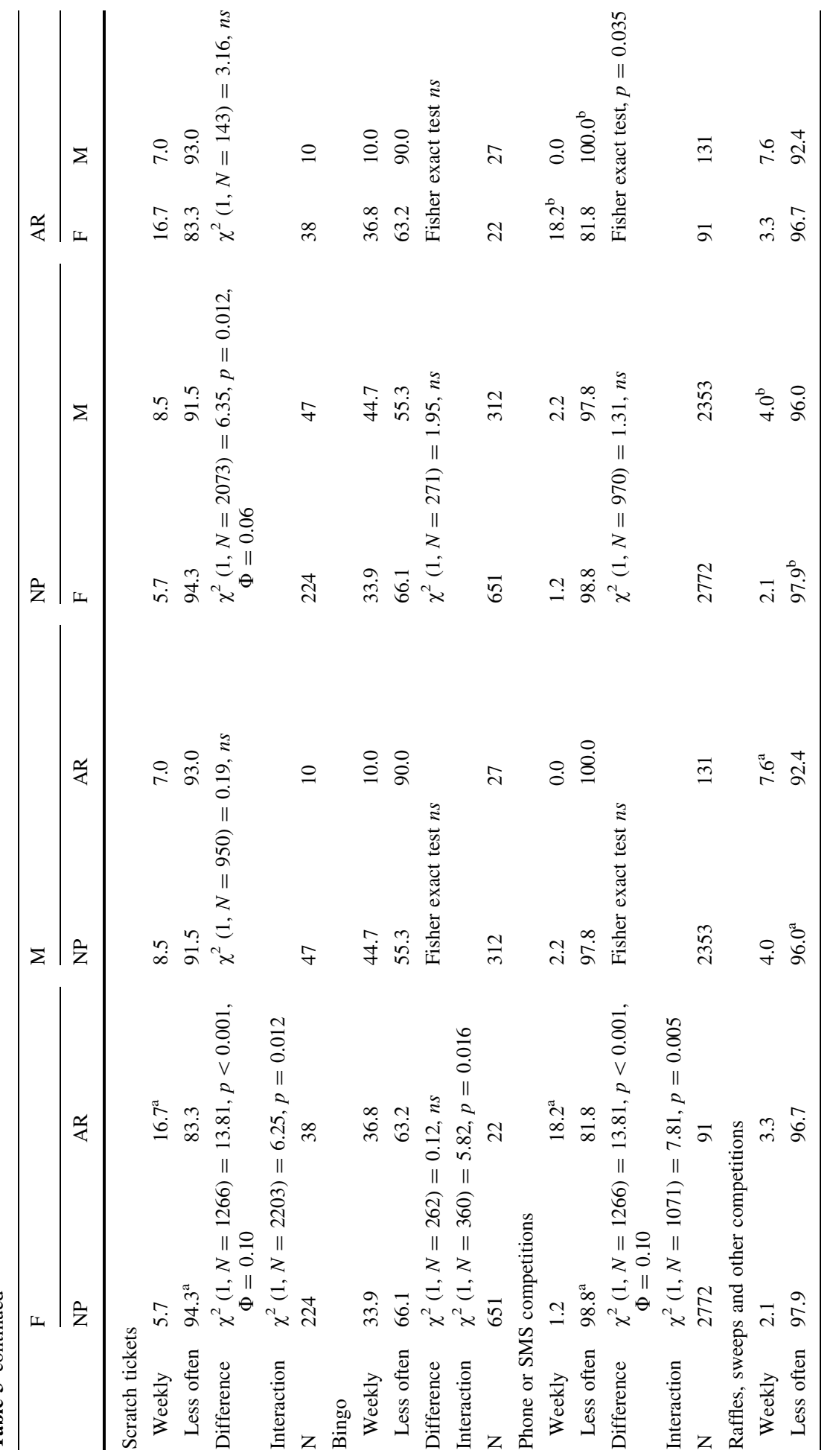




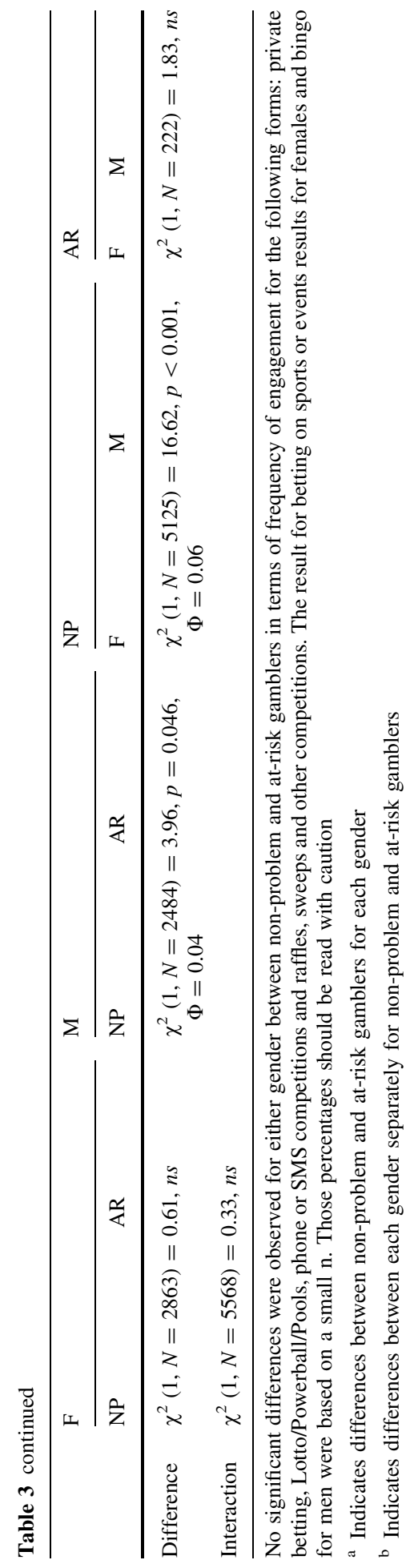


For both genders, those engaging less than weekly in EGMs, table games and race betting were significantly more likely to be non-problem gamblers. The same was true for males on keno, sports betting and raffles/sweeps/competitions, and for females on scratch tickets and phone/SMS competitions.

Significant interactions were observed for sports betting, scratch tickets, bingo and phone/SMS competitions, although the sports betting and bingo results were based on small numbers. Results for scratch tickets and phone/SMS competitions were more strongly related to at-risk gambling for females than for males.

\section{EGM Playing Behaviours}

Amongst both genders, those playing EGMs at three or more venues were significantly more likely to be at-risk gamblers (female AR $62.1 \%$, female NP $34.8 \%, \chi^{2}$ (3, $N=789)=41.81, p<0.001, \Phi=0.23$; male AR $53.4 \%$, male NP $33.9 \%, \chi^{2}(3$, $N=881)=27.87, p<0.001, \Phi=0.18)$. Those playing at only one venue were significantly more likely to be non-problem gamblers (female NP $39.9 \%$, female AR $17.6 \%$, male NP $39.1 \%$, male AR $24.9 \%$ ). This pattern did not differ significantly across genders, $\chi^{2}(3, N=1671)=3.07$, ns.

Often/always playing more than one credit per EGM line was associated with at-risk gamblers, with this effect more pronounced for males (male AR 64.0\%, male NP $39.1 \%$ ). Rarely/never playing more than one credit per line was more prominent among male nonproblem gamblers $(42.4 \%)$ compared to male at-risk gamblers $(19.2 \%), \chi^{2}(4$, $N=874)=51.75, p<0.001, \Phi=0.24$. A similar pattern was observed for female gamblers $\left(\chi^{2}(4, N=754)=10.06, p=0.039, \Phi=0.12\right)$, although a significant interaction term $\left(\chi^{2}(4, N=1626)=9.99, p=0.041\right)$ revealed a significantly more pronounced result for males than females.

One cent EGMs were significantly more popular amongst non-problem gamblers of both genders (female NP $55.5 \%$, female AR $37.9 \%, \chi^{2}(5, N=776)=25.50, p<0.001$, $\Phi=0.18$; male NP $43.8 \%$, male AR $\left.29.5 \%, \chi^{2}(5, N=858)=22.39, p<0.001, \Phi=0.16\right)$. This result did not differ significantly between genders, $\chi^{2}(5, N=1634)=8.00$, ns.

\section{Race Wagering Behaviours}

Race bets other than win/place, each way or trifectas were associated with at-risk gambling for both genders (female AR $26.8 \%$, female NP $8.7 \%, \chi^{2}(3, N=409)=12.96$, $p=0.005, \Phi=0.18$; male AR $20.6 \%$, male NP $8.0 \%, \chi^{2}(3, N=781)=42.02$, $p<0.001, \Phi=0.23)$. Trifecta betting was associated with at-risk bettors $(24.1 \%$ compared to $11.3 \% \mathrm{NP}$ ) amongst males. Male at-risk gamblers were significantly less likely to bet on win/place (NP $60.0 \%$, AR $42.6 \%$ ) or each way outcomes (NP $20.8 \%$, AR $12.8 \%$ ), compared to non-problem gamblers. The overall pattern of results did not differ significantly between genders, $\chi^{2}(3, N=1191)=2.53, n s$.

\section{Money Management}

For both genders, at-risk gamblers were significantly more likely to bring EFTPOS/ATM cards with them when gambling (female AR $35.6 \%$, female NP $17.2 \%, \chi^{2}$ (3, $N=1818)=46.14, p<0.001, \Phi=0.16$; male AR $39.6 \%$, male NP $17.1 \%, \chi^{2}(3$, 
$N=1988)=87.20, p<0.001, \Phi=0.21)$, and significantly less likely to not bring any cards at all (female AR $28.3 \%$, female NP $49.4 \%$; male AR $21.2 \%$, male NP $41.7 \%$ ). There were no significant differences between risk groups in each gender for bringing a credit card or bringing both an EFTPOS/ATM and credit card. There was no significant interaction, $\chi^{2}(3, N=3807)=3.37, n s$.

At-risk gamblers of both genders were significantly more likely to bring larger amounts of cash to gambling venues, particularly $\$ 100$ or more, compared to non-problem gamblers (female AR $19.7 \%$, female NP $6.1 \%, \chi^{2}(5, N=1852)=87.87, p<0.001, \Phi=0.22$; male AR $39.6 \%$, male NP $\left.17.7 \%, \chi^{2}(5, N=2035)=87.96, p<0.001, \Phi=0.21\right)$. Both at-risk and non-problem male gamblers were significantly more likely to bring more than $\$ 100$ cash compared to female at-risk and non-problem gamblers $\left(\chi^{2}(5, N=3425)=130.77\right.$, $p<0.001, \Phi=0.20$ and $\chi^{2}(5, N=462)=23.48, p<0.001, \Phi=0.23$ respectively). Nonproblem gamblers of both genders were significantly more likely to bring up to $\$ 20$ (female NP $40.4 \%$, female AR $13.0 \%$; male NP $31.3 \%$, male AR $14.4 \%$ ).

At-risk gamblers of both genders were significantly more likely than others to withdraw extra money at least once while at a gambling venue (female AR $57.6 \%$, female NP $14.3 \%, \chi^{2}(5, N=958)=194.50, p<0.001, \Phi=0.45$; male AR $63.3 \%$, male NP $\left.15.2 \%, \chi^{2}(5, N=1215)=295.74, p<0.001, \Phi=0.49\right)$, although the result did not differ significantly by gender, $\chi^{2}(5, N=2176)=5.51$, $n s$.

\section{Main Reasons for Gambling on Highest Spending Form}

Significant differences were observed between risk groups for gambling motivations for both males $\left(\chi^{2}(4, N=2034)=30.53, p<0.001, \Phi=0.12\right)$ and females $\left(\chi^{2}(4\right.$, $N=1854)=61.87, p<0.001, \Phi=0.18)$. Post hoc tests revealed that, for both genders, at-risk gamblers were significantly less likely to report gambling to win money $(27.9 \%$ females, $31.6 \%$ males vs. $44.4 \%$ NP females, $44.5 \%$ NP males) or to raise money for charity ( $0.6 \%$ females, $0.7 \%$ males vs $6.4 \%$ NP females, $2.7 \%$ NP males), but were significantly more likely to select options recoded into "other" due to small cell sizes (31.8\% females, $17.9 \%$ males vs $12.9 \%$ NP females, $10.9 \%$ NP males). "Other" responses included: escaping boredom, relieving stress, taking the respondent's mind off things and various self-reported reasons. Male at-risk gamblers were significantly more likely to report gambling for general entertainment (26.7 vs $19.2 \%$ NP males), while the same result was not statistically significant for females. There was no significant interaction effect $\left(\chi^{2}(4, N=3888)=4.61, n s\right)$.

\section{Health}

\section{Substance Use}

At-risk gamblers of both genders were significantly more likely to have smoked in the last 12 months (female AR 49.2\%, female NP $24.4 \%, \chi^{2}(1, N=1854)=50.46, p<0.001$, $\Phi=0.17$; male AR $51.9 \%$, male NP $28.1 \%, \chi^{2}(1, N=2034)=64.37, p<0.001$, $\Phi=0.18$ ) and to be current smokers (female AR $42.5 \%$, female NP $18.7 \%, \chi^{2}(1$, $N=1854)=54.74, p<0.001, \Phi=0.17$; male AR $45.3 \%$, male NP $21.0 \%, \chi^{2}(1$, $N=2034)=77.88, p<0.001, \Phi=0.20)$. There were no significant interactions for 
either smoking variable $\left(\chi^{2}(1, N=3888)=0.20, n s\right.$ and $\chi^{2}(1, N=3888)=0.03, n s$ respectively).

At-risk gamblers of both genders were significantly more likely to show signs of clinical alcohol abuse (female AR $15.3 \%$, female NP $6.5 \%$; male AR $17.0 \%$, male NP $9.6 \%$ ) or to have moderate (female AR $6.5 \%$, female NP $2.5 \%$; male AR $12.6 \%$, male NP $5.6 \%$ ) or high (female AR $2.4 \%$, female NP $0.2 \%$; male AR $3.6 \%$, male NP $0.8 \%$ ) clinical alcohol abuse compared to non-problem gamblers (female $\chi^{2}(4, N=1487)=36.35$, $p<0.001, \Phi=0.16$; male $\left.\chi^{2}(4, N=1819)=55.17, p<0.001, \Phi=0.17\right)$. The interaction term comparing genders was not statistically significant $\left(\chi^{2}(4, N=3299)=1.86\right.$, $n s)$. Non-problem gamblers were significantly more likely to show no signs of clinical alcohol abuse compared to at-risk gamblers (female NP $80.9 \%$, female AR $64.5 \%$; male NP $68.3 \%$, male AR $48.6 \%$ ).

\section{Mental Health}

For both genders, at-risk gamblers were significantly more likely to have mild (female AR $13.9 \%$, female NP $5.6 \%$; male AR $13.4 \%$, male NP $3.9 \%$ ), moderate (female AR $11.1 \%$, female NP $2.3 \%$; male AR $8.8 \%$, male NP $1.3 \%$ ), or severe (female AR $15.0 \%$, female NP $1.9 \%$; male AR $6.0 \%$, male NP $1.4 \%$ ) mental disorders compared to nonproblem gamblers (female $\chi^{2}(3, N=1856)=161.40, p<0.001, \Phi=0.30$; male $\chi^{2}(3$, $N=2033)=140.84, p<0.001, \Phi=0.26$ ). This result did not differ significantly between genders. Conversely, non-problem gamblers of both genders were significantly more likely to be in the 'likely to be well' category on the K10 (female AR $60.0 \%$, female NP $90.2 \%$; male AR $71.8 \%$, male NP $93.5 \%)$. Both at-risk $\left(\chi^{2}(3, N=464)=12.36\right.$, $p=0.006, \Phi=0.16)$ and non-problem $\left(\chi^{2}(3, \quad N=3425)=13.39, \quad p=0.004\right.$, $\Phi=0.06)$ male gamblers were significantly more likely than female counterparts to be well.

At-risk gamblers of both genders (47.5\% females, $28.9 \%$ males) were significantly more likely to have experienced trauma or hardship compared to non-problem gamblers (25.0\% females, $14.2 \%$ males), $\chi^{2}(1, N=1854)=41.53, p<0.001, \Phi=0.15$ and $\chi^{2}$ $(1, N=2033)=38.40, p<0.001, \Phi=0.14$ respectively Both at-risk and non-problem female gamblers were significantly more likely to have experienced trauma or hardship compared to males. However there was no significant interaction, $\chi^{2}(1$, $N=3887)=0.21, n s$.

\section{Physical Health}

Amongst both genders, at-risk gamblers were significantly more likely to report lung conditions including asthma $\left(21.0 \%\right.$ AR females, $10.7 \% \mathrm{NP}$ females, $\chi^{2}(1$, $N=1855)=13.81, p<0.001, \Phi=0.09 ; 15.4 \%$ AR males, $9.0 \%$ NP males, $\chi^{2}(1$, $N=2034)=11.49, p<0.001, \Phi=0.08)$, depression $(31.8 \%$ AR females, $11.1 \% \mathrm{NP}$ females, $\chi^{2}(1, N=1854)=61.07, p<0.001, \Phi=0.18 ; 25.6 \%$ AR males, $6.6 \% \mathrm{NP}$ males, $\left.\chi^{2}(1, N=2034)=104.76, p<0.001, \Phi=0.23\right)$, anxiety disorders $(26.8 \% \mathrm{AR}$ females, $9.5 \%$ NP females, $\chi^{2}(1, N=1855)=48.99, p<0.001, \Phi=0.16 ; 22.5 \% \mathrm{AR}$ males, $5.6 \%$ NP males, $\left.\chi^{2}(1, N=2033)=95.52, p<0.001, \Phi=0.22\right)$ and obesity (20.1\% female AR gamblers, $11.4 \%$ female NP gamblers, $\chi^{2}(1, N=1854)=11.42$, $p=0.001, \Phi=0.08 ; 14.4 \%$ AR males, $7.0 \%$ NP males, $\chi^{2}(1, N=2034)=17.88$, $p<0.001, \Phi=0.09$ ). Male at-risk gamblers were significantly more likely to report other health conditions $\left(16.5 \%\right.$ AR males, $11.8 \% \mathrm{NP}$ males, $\chi^{2}(1, N=2034)=5.00$, 
$p=0.025, \Phi=0.05)$, while female at-risk gamblers $(8.4 \%)$ were significantly more likely to report diabetes compared to non-problem gamblers $\left(4.7 \%, \chi^{2}(1\right.$, $N=1854)=4.51, p=0.034, \Phi=0.05)$. Female non-problem gamblers were significantly more likely than male counterparts to have experienced depression $(11.1 \%$ vs $6.6 \%$ for NP males, $\left.\chi^{2}(1, N=3425)=21.28, p<0.001, \Phi=0.08\right)$, anxiety $(9.5 \%$ vs $5.6 \%$ for NP males, $\left.\chi^{2}(1, N=3425)=18.60, p<0.001, \Phi=0.07\right)$, or obesity $(9.5 \%$ vs $5.6 \%$ for NP males, $\left.\chi^{2}(1, N=3424)=19.62, p<0.001, \Phi=0.08\right)$, with no significant gender differences between at-risk gamblers. No significant differences were observed for either gender for heart conditions, diabetes or cancer. There were no significant interactions for any health condition.

\section{Multivariate Analyses}

Preceding analyses comparing non-problem and at-risk gamblers identified important factors then included in multivariate analyses:

- Age (dummy-coded, 18-24 as reference group)

- Speaking a language other than English at home

- Education (dummy-coded, university as reference group)

- Household type (recoded as couple with child(ren), couple without children, group household and other, then dummy-coded with couple with child(ren) as reference group)

- Employment (dummy-coded, "not in workforce or away from work" and "unemployed" as reference group)

- Engagement in each main gambling form

- Main reasons for gambling on highest spend activity (dummy-coded, "other" as the reference group, "to raise money for charity" also collapsed into reference group)

Other variables were not included because of high correlation with included variables, because relevant bivariate analyses were either non-significant or had very low effect sizes, or because relatively few respondents were asked or answered the question.

The model was run separately for males and for females, predicting at-risk gambling status (i.e. PGSI 0-2 vs PGSI $3+$, coded as 0 and 1 respectively).

\section{Risk Factors Amongst Females}

All questions in the analysis were completed by 1820 females: 1648 non-problem gamblers and 172 at-risk gamblers. The overall model was statistically significant $\left(\chi^{2}(28\right.$, $N=1820)=252.04, p<0.001)$, correctly predicting $99.3 \%$ of non-problem gamblers, but only $11.5 \%$ of at-risk gamblers.

Significant predictors of at-risk status amongst female gamblers were: 18-24 years old (compared to being 65+), speaking a language other than English at home, living in a group household (compared to couple with children), unemployed or not in the workforce (compared to both full-time and part-time employment), betting on private betting, EGMs, scratch tickets or bingo (compared to not betting on those forms), not betting on raffles/ sweeps/other competitions (compared to betting on them), and gambling for reasons other than social reasons, to win money or for general entertainment (Table 4). 
Table 4 Results for the predictors in the multivariate analysis for females

\begin{tabular}{llllll}
\hline Predictor Level & B & Odds ratio & $\begin{array}{l}\text { CI lower } \\
\text { Bound }\end{array}$ & $\begin{array}{l}\text { CI upper } \\
\text { Bound }\end{array}$ \\
\hline
\end{tabular}

Age (ref: 18-24)

$\begin{array}{lllll}25-34 & 0.20 & 1.22 & 0.60 & 2.49 \\ 35-44 & 0.26 & 1.30 & 0.63 & 2.66 \\ 45-54 & 0.54 & 1.71 & 0.87 & 3.35 \\ 55-64 & 0.03 & 1.03 & 0.49 & 2.17 \\ 65 \text { or older } & -1.01 & 0.36^{*} & 0.16 & 0.82\end{array}$

Language other than English at home (ref: no)

$\begin{array}{llll}0.64 & 1.90 * & 3.15\end{array}$

Education (ref: Year 10 or lower)

$\begin{array}{lllll}\text { University } & -0.36 & 0.70 & 0.40 & 1.21 \\ \text { TAFE or trade qualification } & -0.40 & 0.67 & 0.40 & 1.14 \\ \text { Year 12 } & -0.35 & 0.70 & 0.43 & 1.14\end{array}$

Household type (ref: couple with children)

$\begin{array}{lrlll}\text { Couple without children } & -0.11 & 0.89 & 0.54 & 1.49 \\ \text { Group household } & 1.45 & 4.25^{*} & 1.89 & 9.54 \\ \text { Other } & 0.21 & 1.23 & 0.79 & 1.92\end{array}$

Employment status (ref: unemployed or not at work)

$\begin{array}{lllll}\text { Full-time employment } & -0.55 & 0.58^{*} & 0.36 & 0.94 \\ \text { Part-time employment } & -0.48 & 0.62 * & 0.39 & 0.99\end{array}$

Forms of gambling (ref: do not participate)

$\begin{array}{lrlll}\text { Private betting } & 0.87 & 2.39^{*} & 1.02 & 5.57 \\ \text { EGMs } & 2.14 & 8.49^{*} & 5.30 & 13.58 \\ \text { Table games } & -0.28 & 0.76 & 0.36 & 1.60 \\ \text { Horse/harness/greyhound } & 0.09 & 1.09 & 0.71 & 1.67 \\ \text { Sports or events } & 0.35 & 1.42 & 0.56 & 3.64 \\ \text { Keno } & 0.04 & 1.04 & 0.52 & 2.06 \\ \text { Lotto/Powerball/Pools } & 0.06 & 1.06 & 0.69 & 1.63 \\ \text { Scratch tickets } & 0.44 & 1.55^{*} & 1.07 & 2.25 \\ \text { Bingo } & 1.11 & 3.03^{*} & 1.81 & 5.08 \\ \text { Phone/SMS competitions } & -0.07 & 0.94 & 0.55 & 1.60 \\ \text { Raffles, sweeps, etc. } & -0.51 & 0.60^{*} & 0.42 & 0.87 \\ \text { gambling (ref: other) } & & & & 0.66 \\ \text { Social reasons } & -0.94 & 0.39^{*} & 0.23 & 0.67 \\ \text { To win money } & -0.87 & 0.42^{*} & 0.26 & 0.89 \\ \text { General entertainment } & -0.63 & 0.54^{*} & 0.32 & \end{array}$

Asterisks (*) indicate significant predictors in the regression model. The statistics reported are B, Odds ratio (with asterisks indicating significant predictors) and the lower and upper bounds for the $95 \%$ confidence interval for each predictor. Thus, a positive B indicates that the predictor is associated with at-risk gamblers (compared to the reference group) for that gender, whereas a negative B indicates that the predictor is associated with non-problem gamblers. Those who were excluded from the analyses due to missing data were compared to those who were included. There were some minor demographic and behavioural differences between the groups, but the effect sizes were small and most differences were in the order of $3 \%$, indicating that the differences were likely to be due to the large sample size. Thus, the missing data were not considered to be particularly problematic for this model 


\section{Risk Factors Amongst Males}

Valid data from 2005 males were included: 1722 non-problem gamblers and 283 at-risk gamblers. The overall model was statistically significant $\left(\chi^{2}(28, N=2005)=369.39\right.$, $p<0.001$ ), correctly predicting $98.3 \%$ of non-problem gamblers and $26.4 \%$ of at-risk gamblers.

Significant predictors of male at-risk gambling status were: 18-24 years old (compared to being 65 or older), speaking a language other than English at home, Year 10 or lower education (compared to Year 12 or university education), living in a group household (compared to couple with children), unemployed or not in the workforce (compared to fulltime employment), betting on EGMs, table games, races, sports, or lottery-type games (compared to not betting on those forms), not betting on raffles/sweeps/other competitions (compared to betting on them), and gambling for reasons other than social reasons, to win money or for general entertainment (Table 5).

\section{Comparison of Risk Factor Models for Females and Males}

Tables 4 and 5 allow identification of significantly different predictors for females and males by comparing the odds ratios from one model to the confidence interval for the other.

Aged 45-54 (compared to 18-24), and betting on private betting, EGMs and scratch tickets were stronger predictors of at-risk gambling for females. Stronger predictors for males were university education (compared to Year 10 or lower), unemployed (compared to working full-time), and betting on table games, races and lottery-type games.

\section{Discussion}

Consistent with previous studies (Williams et al. 2012a), this study found that significantly higher proportions of males scored as low risk, moderate risk and problem gamblers compared to females, suggesting gender-based differences in risk factors. This study supported several risk factors for gambling problems identified in previous studies, but also revealed important differences by gender. Gender-based differences were most pronounced for participation in various gambling forms. The only form posing a risk factor for both genders was EGMs, as previously implicated (Dowling et al. 2005; Williams et al. 2012a). This risk was heightened for female compared to male at-risk gamblers, and amongst 45-54 year old women, in accordance with prior research (Crisp et al. 2004; Welte et al. 2007). This was despite a more pronounced association with higher problem gambling severity amongst men of frequently playing more than one credit per EGM line, a behaviour associated with EGM problem gamblers in general (Hing and Breen 2002). This finding supports suggestions to reduce maximum bet size to reduce EGM-related harms because problem gamblers are most likely to bet large amounts (Livingstone et al. 2008; Williams et al. 2012b), and because reducing maximum bet size significantly decreases time and money spent (Blaszczynski et al. 2001).

Both male and female at-risk gamblers were more likely than their non-problem counterparts to play EGMs at least weekly and at three or more venues, but were less likely to play one cent EGMs. Thus, although risks with EGMs appear heightened amongst middle-aged women, frequent EGM gambling at multiple venues using higher denomination EGMs appear generic risk factors across genders. These results suggest that 
Table 5 Results for the predictors in the multivariate analysis for males

\begin{tabular}{lllll}
\hline Predictor Level & B & Odds ratio & $\begin{array}{l}\text { CI lower } \\
\text { Bound }\end{array}$ & $\begin{array}{l}\text { CI upper } \\
\text { Bound }\end{array}$ \\
\hline
\end{tabular}

Age (ref: 18-24)

$\begin{array}{lllll}25-34 & -0.09 & 0.92 & 0.56 & 1.51 \\ 35-44 & -0.19 & 0.82 & 0.48 & 1.42 \\ 45-54 & -0.37 & 0.69 & 0.39 & 1.23 \\ 55-64 & -0.17 & 0.84 & 0.46 & 1.54 \\ 65 \text { or older } & -1.34 & 0.26^{*} & 0.13 & 0.55\end{array}$

Language other than English at home (ref: no)

$\begin{array}{llll}0.84 & 2.32 * & 1.61 & 3.35\end{array}$

Education (ref: Year 10 or lower)

$\begin{array}{lllll}\text { University } & -0.87 & 0.42^{*} & 0.27 & 0.66 \\ \text { TAFE or trade qualification } & -0.34 & 0.71 & 0.48 & 1.06 \\ \text { Year 12 } & -0.46 & 0.63^{*} & 0.42 & 0.94\end{array}$

Household type (ref: couple with children

$\begin{array}{lrlll}\text { Couple without children } & -0.19 & 0.83 & 0.55 & 1.25 \\ \text { Group household (not related) } & 1.14 & 3.13^{*} & 1.75 & 5.59 \\ \text { Other } & 0.14 & 1.15 & 0.79 & 1.68\end{array}$

Employment status (ref: unemployed or not at work)

$\begin{array}{lllll}\text { Full-time employment } & -1.09 & 0.34^{*} & 0.21 & 0.53 \\ \text { Part-time employment } & -0.51 & 0.60 & 0.35 & 1.02\end{array}$

Forms of gambling (ref: do not participate)

$\begin{array}{lrlll}\text { Private betting } & 0.29 & 1.34 & 0.87 & 2.06 \\ \text { EGMs } & 1.66 & 5.25^{*} & 3.77 & 7.31 \\ \text { Table games } & 0.87 & 2.38^{*} & 1.63 & 3.46 \\ \text { Horse/harness/greyhound } & 0.45 & 1.56^{*} & 1.13 & 2.16 \\ \text { Sports or events } & 0.69 & 1.99^{*} & 1.34 & 2.98 \\ \text { Keno } & -0.16 & 0.85 & 0.47 & 1.55 \\ \text { Lotto/Powerball/Pools } & 0.99 & 2.68^{*} & 1.83 & 3.92 \\ \text { Scratch tickets } & -0.26 & 0.78 & 0.54 & 1.11 \\ \text { Bingo } & 0.54 & 1.71 & 0.51 & 5.76 \\ \text { Phone/SMS competitions } & -0.07 & 0.94 & 0.57 & 1.54 \\ \text { Raffles, sweeps, etc. } & -0.33 & 0.72^{*} & 0.53 & 0.98 \\ \text { or gambling (ref: other) } & & & & \\ \text { Social reasons } & -0.62 & 0.54^{*} & 0.34 & 0.86 \\ \text { To win money } & -0.74 & 0.48^{*} & 0.31 & 0.74 \\ \text { General entertainment } & -0.72 & 0.49^{*} & 0.30 & 0.78\end{array}$

Asterisks (*) indicate significant predictors in the regression model. The statistics reported are B, Odds ratio (with asterisks indicating significant predictors) and the lower and upper bounds for the $95 \%$ confidence interval for each predictor. Thus, a positive B indicates that the predictor is associated with at-risk gamblers (compared to the reference group) for that gender, whereas a negative B indicates that the predictor is associated with non-problem gamblers. Those who were excluded from the analyses due to missing data were compared to those who were included. There were some minor demographic and behavioural differences between the groups, but the effect sizes were small and most differences were in the order of $3 \%$, indicating that the differences were likely to be due to the large sample size. Thus, the missing data were not considered to be particularly problematic for this model 
regular EGM gamblers in general, and middle-aged female EGM gamblers in particular, are appropriate targets for public health campaigns aimed at lowering risk of problem gambling.

Although gambling problems amongst women are heavily skewed towards difficulties with EGMs (Delfabbro 2012; Holdsworth et al. 2012), this study found a wider range of forms posing risk factors for men. These included table games, as also reported elsewhere (Delfabbro 2012; Perese et al. 2005; Williams et al. 2012b), and race and sports betting, which may be increasingly problematic due to their online availability. A large Australian study revealed that risk factors for higher problem gambling severity among Internet gamblers included betting on sports, races and poker (Gainsbury et al. 2014). Sports betting is a relatively new growth activity, with high problem gambling rates amongst regular and online sports bettors (Hing et al. 2014b, d). Efforts to reduce risk factors need to accommodate migration of many gamblers to the online environment (Hing et al. 2014a).

Certain gambling motivations were also implicated as risk factors for both genders. These related to gambling for reasons other than social reasons, to win money or for general entertainment, with these other reasons including escaping boredom, relieving stress, and taking the respondent's mind off things. Gambling to escape and for mood regulation increases risks for gambling problems (Blaszczynski and Nower 2002; Nower and Blaszczynski 2010), with women more likely than men to gamble for mood regulation (Lloyd et al. 2010) and to escape everyday problems, boredom and loneliness (Grant and Kim 2002; Sacco et al. 2011). Several studies of women's gambling have noted EGM use as a form of avoidant or emotion-based coping (Schull 2002; Thomas 1998; Thomas and Moore 2003), which may explain their higher risk for EGM-associated problems. Risk reduction measures could discourage gambling to escape from negative mood states, particularly amongst women.

In contrast to some distinctive risk factors for men and for women, this study found nearly identical demographic risk factors between genders which generally aligned with findings from non-gendered research (Castrén et al. 2013b; Delfabbro 2012; Johansson et al. 2009; Perese et al. 2005). These included young adult age, not speaking English at home, living in a group household, and being unemployed or not in the workforce. For male at-risk gamblers, low education was also a risk factor. These findings confirm that young adults are primary targets for risk reduction measures, and that messages should be sensitive to those from non-English-speaking backgrounds and with limited education.

The study has several limitations which could be avoided in future research. Relatively small numbers of problem gamblers necessitated their combining with moderate risk gamblers, obscuring any gender differences within each of these groups. Separate analyses for problem and moderate risk gamblers may also have yielded models with greater explanatory power. Future studies should consider a two-stage research design to improve the likelihood of obtaining adequate numbers of problem gamblers for separate analyses, given their low prevalence in the population. Several potential risk factors were asked only of atrisk gamblers in the original study which limited comparisons amongst PGSI groups. Use of a non-validated version of the PGSI may have affected assignment to PGSI groups. Most other measures were unvalidated, so it is difficult to assess whether related findings reflect true differences or measurement artefacts. Sample sizes were quite different across analyses, yielding different levels of statistical power. Where numbers were small, some results may be unlikely to generalise or replicate. 


\section{Conclusion}

This study has presented a gender-based analysis of risk factors for gambling problems. Its value lies in identifying some distinctive differences between genders, corroboration and strengthening of previous findings through validation in a large representative population survey, use of multivariate analyses, and identification of high risk groups for targeting with appropriate interventions. These comprise young adults, especially males; middleaged women who play EGMs; non-English speaking populations; frequent gamblers on EGMs, table games, race and sports betting; and gamblers motivated by escape-based reasons. Identifying distinctive risk factors by gender may also prompt more focus on the public health of women in relation to gambling, while still recognising that males are most at-risk of gambling problems.

Acknowledgments The Victorian Responsible Gambling Foundation provided financial support for this project and approved this manuscript for publication.

Conflict of interest All authors have received funding support and provided consultancies to organisations directly and indirectly benefiting from gambling, including Australian governments and industry operators. They each declare no conflict of interest in relation to this manuscript.

\section{References}

Afifi, T. O., Cox, B. J., Martens, P. J., Sareen, J., \& Enns, M. W. (2010). The relationship between problem gambling and mental and physical health correlates among a nationally representative sample of Canadian women. Canadian Journal of Public Health, 101(2), 171-175.

Binde, P. (2011). What are the most harmful forms of gambling? Analyzing problem gambling prevalence surveys. CEFOS working papers 12. Retrieved 22-01-15 from http://www.utbildning.gu.se/ digitalAssets/1327/1327132_cefos-wp12.pdf

Blanco, C., Petry, N., Stinson, F. S., \& Grant, B. F. (2006). Sex differences in subclinical and DSM-IV pathological gambling: Results from the National Epidemiologic survey on alcohol and related conditions. Psychological Medicine, 36, 943-953.

Blaszczynski, A., \& Nower, L. (2002). A pathways model of problem and pathological gambling. Addiction, 97, 487-499.

Blaszczynski, A., Sharpe, L., \& Walker, M. (2001). Final report: The assessment of the impact of the reconfiguration on electronic gaming machines as harm minimisation strategies for problem gambling. Sydney: University of Sydney.

Castrén, S., Basnet, S., Pankakoski, M., Ronkainen, J.-E., Helakorpi, S., Uutela, A., \& Lahti, T. (2013a). An analysis of problem gambling among the Finnish working-age population: A population survey. $B M C$ Public Health, 13(1), 519.

Castrén, S., Basnet, S., Salonen, A. H., Pankakoski, M., Ronkainen, J. E., Alho, H., \& Lahti, T. (2013b). Factors associated with disordered gambling in Finland. Substance Abuse Treatment, Prevention, and Policy, 8, 24.

Christensen, D. R., Dowling, N. A., Jackson, A. C., \& Thomas, S. A. (2014). Gambling participation and problem gambling severity in a stratified random survey: Findings from the second social and economic impact study of gambling in Tasmania. Journal of Gambling Studies. doi:10.1007/s10899-0149495-9.

Crisp, B. R., Thomas, S. A., Jackson, A. C., Smith, S., Borrell, J., Ho, W. Y., et al. (2004). Not the same: A comparison of female and male clients seeking treatment from problem gambling counseling services. Journal of Gambling Studies, 20, 283-299.

Dannon, P. N., Lowengrub, K., Shalgi, B., Sasson, M., Tuson, L., Saphir, Y., \& Kotler, M. (2006). Dual psychiatric diagnosis and substance abuse in pathological gamblers: A preliminary gender comparison study. Journal of Addictive Diseases, 25, 49-54.

Delfabbro, P. H. (2009). Australasian gambling review (4th ed.). Adelaide: Independent Gambling Authority. 
Delfabbro, P. H. (2012). Australasian gambling review (5th ed.). Adelaide: Independent Gambling Authority.

Dowling, N. A. (2013). The cognitive-behavioral treatment of female problem gambling. In D. C. S. Richard, A. Blaszczynski, \& L. Nower (Eds.), The Wiley-Blackwell handbook for disordered gambling. Hoboken: Wiley.

Dowling, N., Smith, D., \& Thomas, T. (2005). Electronic gaming machines: Are they the 'crack-cocaine' of gambling? Addiction, 100, 33-45.

Erickson, L., Molina, C. A., Ladd, G. T., Pietrzak, R. H., \& Petry, N. M. (2005). Problem and pathological gambling are associated with poorer mental and physical health in older adults. International Journal of Geriatric Psychiatry, 20(8), 754-759.

Ewing, J. A. (1984). Detecting alcoholism. JAMA: The Journal of the American Medical Association, 252(14), 1905-1907.

Ferris, J., \& Wynne, H. (2001). The Canadian problem gambling index: Final report. Ottawa: Canadian Centre on Substance Abuse.

Gainsbury, S. M., Russell, A., Hing, N., Wood, R., Lubman, D. I., \& Blaszczynski, A. (2014). The prevalence and determinants of problem gambling in Australia: Assessing the impact of interactive gambling and new technologies. Psychology of Addictive Behaviors, 28(3), 769-779.

Grant, J. E., Chamberlain, S. R., Schreiber, L., \& Odlaug, B. L. (2012). Gender-related clinical and neurocognitive differences in individuals seeking treatment for pathological gambling. Journal of Psychiatric Research, 46(9), 1206-1211.

Grant, J. E., \& Kim, S. W. (2002). Gender differences in pathological gamblers seeking medication treatment. Comprehensive Psychiatry, 43, 56-62.

Hare, S. (2009). A study of gambling in Victoria: Problem gambling from a public health perspective. Melbourne: Department of Justice.

Hing, N., \& Breen, H. (2001a). Profiling lady luck: An empirical study of gambling and problem gambling amongst female club members. Journal of Gambling Studies, 17(1), 47-69.

Hing, N., \& Breen, H. (2001b). An empirical study of sex differences in gaming machine play among club members. International Gambling Studies, 1(1), 66-86.

Hing, N., \& Breen, H. (2002). A profile of gaming machine players in clubs in Sydney, Australia. Journal of Gambling Studies, 18(2), 185-205.

Hing, N., Cherney, L., Blaszczynski, A., Gainsbury, S., \& Lubman, D. (2014a). Do advertising and promotions for online gambling increase gambling consumption? An exploratory study. International Gambling Studies, 14(3), 394-409.

Hing, N., Gainsbury, S., Blaszczynski, A., Wood, R., Lubman, D., \& Russell, A. (2014b). Interactive gambling. Melbourne: Gambling Research Australia.

Hing, N., Russell, A. M. T, Gainsbury, S., \& Blaszczynski, A. (2014c). Help-seeking behaviours of internet gamblers based on most problematic mode of gambling. Journal of Medical Internet Research. doi:10. 2196/jmir.3781

Hing, N., Vitartas, P., \& Lamont, M. (2014d). Promotion of gambling and live betting odds during televised sport: Influences on gambling participation and problem gambling. Brisbane: Queensland Department of Justice and Attorney-General.

Holdsworth, L., Hing, N., \& Breen, H. (2012). Exploring women's problem gambling: A review of the literature. International Gambling Studies, 12(2), 199-213.

Johansson, A., Grant, J. E., Kim, S. W., Odlaug, B. L., \& Götestam, K. G. (2009). Risk factors for problematic gambling: A critical literature review. Journal of Gambling Studies, 25(1), 67-92.

Lee, H. P., Chae, P. K., Lee, H. S., \& Kim, Y. K. (2007). The five-factor gambling motivation model. Psychiatry Research, 150(1), 21-32.

Lister, J. (2014). The relationship of gambling goals and loss/win conditions to chasing behaviour during slot machine play. Rutgers University-Graduate School-New Brunswick.

Livingstone, C., Woolley, R., Zazryn, T., Bakacs, L., \& Shami, R. (2008). The relevance and role of gaming machine games and game features on the play of problem gamblers. Adelaide: Independent Gambling Authority.

Lloyd, J., Doll, H., Hawton, K., Dutton, W. H., Geddes, J. R., Goodwin, G. M., \& Rogers, R. D. (2010). How psychological symptoms relate to different motivations for gambling: An online study of Internet gamblers. Biological Psychiatry, 68, 733-740.

Martins, S. S., Tavares, H., da Silva Lobo, D. S., Galetti, A. M., \& Gentil, V. (2004). Pathological gambling, gender, and risk-taking behaviors. Addictive Behaviors, 29, 1231-1235.

McCormack, A., Shorter, G. W., \& Griffiths, M. D. (2013). An examination of participation in online gambling activities and the relationship with problem gambling. Journal of Behavioral Addictions, 2(1), 31-41. 
McCormack, A., Shorter, G. W., \& Griffiths, M. D. (2014). An empirical study of gender differences in online gambling. Journal of Gambling Studies, 30(1), 71-88.

Morasco, B. J., Pietrzak, R. H., Blanco, C., Grant, B. F., Hasin, D., \& Petry, N. M. (2006). Health problems and medical utilization associated with gambling disorders: Results from the National Epidemiologic Survey on Alcohol and Related Conditions. Psychosomatic Medicine, 68(6), 976-984.

Nower, L., \& Blaszczynski, A. (2010). Gambling motivations, money-limiting strategies, and precommitment preferences of problem versus non-problem gamblers. Journal of Gambling Studies, 26, 361-372.

Perese, L., Bellringer, M., \& Abbott, M. (2005). Literature review to inform social marketing objectives and approaches, and behaviour change indicators, to prevent and minimise gambling harm. Auckland: Gambling Research Centre, Auckland University of Technology.

Petry, N. M. (2006). Internet gambling: An emerging concern in family practice medicine? Family Practice, 23(4), 421-426.

Petry, N. M., Stinson, F. S., \& Grant, B. F. (2005). Comorbidity of DSM-IV pathological gambling and other psychiatric disorders: Results from the national epidemiologic survey on alcohol and related conditions. Journal of Clinical Psychiatry, 66, 564-574.

Pietrzak, R. H., Molina, C. A., Ladd, G. T., Kerins, G. J., \& Petry, N. M. (2005). Health and psychosocial correlates of disordered gambling in older adults. The American Journal of Geriatric Psychiatry, 13(6), 510-519.

Pilver, C. E., Libby, D. J., Hoff, R. A., \& Potenza, M. N. (2013). Gender differences in the relationship between gambling problems and the incidence of substance-use disorders in a nationally representative population sample. Drug and Alcohol Dependence, 133(1), 204-211.

Productivity Commission (2010). Gambling, report no. 50. Canberra: Commonwealth of Australia.

Sacco, P., Torres, L. R., Cunningham-Williams, R. M., Woods, C., \& Unick, G. (2011). Differential item functioning of pathological gambling criteria: An examination of gender, race/ethnicity and age. Journal of Gambling Studies, 27, 317-330.

Schull, S. (2002). Escape mechanism: Women, caretaking, and compulsive machine gambling. Berkley: University of California.

Spurrier, M., \& Blaszczynski, A. (2014). Risk perception in gambling: A systematic review. Journal of Gambling Studies, 30(2), 253-276.

Svensson, J., Romild, U., Nordenmark, M., \& Månsdotter, A. (2011). Gendered gambling domains and changes in Sweden. International Gambling Studies, 11(2), 193-211.

Tavares, H., Zilberman, M. L., Beites, F. J., \& Gentil, V. (2001). Gender differences in gambling progression. Journal of Gambling Studies, 17(2), 151-159.

Thomas, S. (1998). Excessive poker machine gambling and anxiety disorders. Gambling Research, 10, 7-13.

Thomas, S., \& Jackson, A. C. (2008). Risk and protective factors, depression and comorbidities in problem gambling. Melbourne: Beyondblue.

Thomas, A., \& Moore, S. (2003). The interactive effects of avoidance coping and dysphoric mood on problem gambling for female and male gamblers. Journal of Gambling Issues. doi: 10.4309/jgi.2003.8.16.

Walker, G. J., Hinch, T. D., \& Weighill, A. (2005). Inter-and intra-gender similarities and differences in motivations for casino gambling. Leisure Sciences, 27(2), 111-130.

Welte, J. W., Barnes, G. M., Wieczorek, W. F., Tidwell, M.-C. O., \& Hoffman, J. H. (2007). Type of gambling and availability as risk factors for problem gambling: A tobit regression analysis by age and gender. International Gambling Studies, 7(2), 183-198.

Welte, J. W., Barnes, G. M., Wieczorek, W. F., Tidwell, M. C. O., \& Parker, J. C. (2004). Risk factors for pathological gambling. Addictive Behaviors, 29(2), 323-335.

Wenzel, H. G., \& Dahl, A. A. (2009). Female pathological gamblers: A critical review of the clinical findings. International Journal of Mental Health and Addiction, 7(1), 190-202.

Williams, R. J., Volberg, R. A., \& Stevens, R. (2012a). The population prevalence of problem gambling: Methodological influences, standardized, rates, jurisdictional differences, and worldwide trends. Guelph: Ontario Problem Gambling Research Centre and the Ontario Ministry of Health and Long Term Care.

Williams, R. J., West, B. L., \& Simpson, R. I. (2012b). Prevention of problem gambling: A comprehensive review of the evidence and identified best practices. Guelph: Ontario Problem Gambling Research Centre.

Wong, G., Zane, N., Saw, A., \& Chan, A. K. K. (2013). Examining gender differences for gambling engagement and gambling problems among emerging adults. Journal of Gambling Studies, 29, $171-189$.

Wood, R. T., \& Williams, R. J. (2011). A comparative profile of the Internet gambler: Demographic characteristics, game-play patterns, and problem gambling status. New Media \& Society, 13(7), 1123-1141. 